This PDF is a selection from a published volume from the National Bureau of Economic Research

Volume Title: Scanner Data and Price Indexes

Volume Author/Editor: Robert C. Feenstra and Matthew

D. Shapiro, editors

Volume Publisher: University of Chicago Press

Volume ISBN: 0-226-23965-9

Volume URL: http://www.nber.org/books/feen03-1

Conference Date: September 15-16, 2000

Publication Date: January 2003

Title: High-Frequency Substitution and the Measurement of Price Indexes

Author: Robert C. Feenstra, Matthew D. Shapiro

URL: http://www.nber.org/chapters/c9733 


\title{
High-Frequency Substitution and the Measurement of Price Indexes
}

\author{
Robert C. Feenstra and Matthew D. Shapiro
}

\subsection{Introduction}

The availability of scanner data for a wide range of household products raises the possibility of improving the measurement of the Consumer Price Index (CPI). Scanner data have a number of potential advantages over price measurements based on survey sampling. Scanner data include the universe of products sold, whereas sampling techniques capture only a small fraction of the population. Scanner data are available at very high frequency, whereas the cost of survey sampling typically limits data to monthly or lower frequency. Finally, scanner data provide simultaneous information on quantities sold in addition to prices, whereas survey techniques typically collect separate data on price and quantity - typically at different frequencies and for different samples.

Ongoing research on using scanner data for measuring the CPI has attempted to mimic the CPI's monthly sampling frame and therefore abstracted from the high-frequency variation in prices and sales. Reinsdorf (1999), for example, uses either monthly unit values or the prices in the third week of each month to construct monthly price indexes for coffee. The collection of prices on a single day, which are then used to construct monthly indexes, corresponds to current practice at the Bureau of Labor Statistics (BLS). This practice has, of course, been constrained by the fact that prices

Robert C. Feenstra is professor of economics at the University of California, Davis, and a research associate of the National Bureau of Economic Research. Matthew D. Shapiro is professor of economics at the University of Michigan and a research associate of the National Bureau of Economic Research.

The authors thank Roger Betancourt, Erwin Diewert, Walter Oi, Marshall Reinsdorf, Julio Rotemberg, and Jack Triplett for very helpful comments. 
are not sampled at frequencies greater than one month, but this constraint is no longer relevant with scanner data.

This paper takes a step toward using the higher-frequency data available from scanner data. It examines how consumer behavior at highfrequency - specifically, weekly purchases of canned tuna-affect the application of index number formulas that have typically been implemented for lower-frequency or time-average data.

Outside of price index research, it has been quite common to use the high-frequency variation in prices and sales available from scanner data. In the marketing literature, it is well recognized that a great deal of substitution occurs across weeks in response to changes in prices and advertising. For example, Van Heerde, Leeflang, and Wittink (2000) have found that store-level data for tuna and toilet tissue contain a dip in sales in the weeks following a promotion, a finding consistent with previous studies at the household level. There is also high substitution between different varieties of tuna, depending on whether they are on sale or not. Given this evidence, it would be highly desirable to construct weekly price indexes in a way that takes this behavior into account.

In order to construct "true" or "exact" price indexes, we need to have a well-specified model of consumer demand, which includes the response to sales and promotions. Betancourt and Gautschi (1992) present a model that distinguishes between purchases and consumption by individuals; in the presence of inventory behavior, these differ over time. Only purchases are observed when one uses data from retail outlets, as we do. Despite this, we show in section 5.2 that by using the Betancourt and Gautschi framework, one can still construct an exact price index that measures the true cost of living (COL) for an individual. This index must compare one planning horizon (e.g., a month or year) to another and cannot be constructed by comparing one week to the next.

In section 5.3, we introduce the data on canned tuna, which are drawn from the ACNielsen academic database. They consist of weekly data over 1993-94 for 316 varieties of tuna over 690 stores. In sections 5.4 and 5.5, we examine how several price indexes perform using these high-frequency price and quantity data. We construct two different types of weekly price indexes. The first, a fixed-base index, compares each week in 1993 to the modal price in 1992, using as weights the average 1992 sales at the modal price. We consider different formulas for the price index, including the Laspeyres, Geometric, and Törnqvist. The fixed-base Laspeyres index corresponds to the arithmetic average of price relatives traditionally used in the CPI. The fixedbase Geometric index corresponds to the "geometric mean" formula now used to produce the elementary price indexes for the majority of the CPI. ${ }^{1}$

1. The BLS uses unweighted averages for both the arithmetic and geometric means of price relatives. The goods to be averaged are probability-sampled using expenditure weights. Given that we will use the universe of observations, we use base-period expenditure weights rather than probability sampling. 
The Törnqvist index uses changing expenditure weights to control for substitution among the goods. We calculate the fixed-base Törnqvist index using the average of the 1992 sales (at the modal price) and the current 1993 weekly sales as weights. Hence, it uses long-term (i.e., base period to present) price relatives. If we take one year as the planning horizon, then this formulation corresponds quite well to our theoretical model of section 5.2.

The second type of index we consider is chained formulas, which update the weights continuously and cumulate period-by-period changes in the price indexes to get long-term changes. The chained Törnqvist constructs the week-to-week Törnqvist using average sales in adjacent weeks and then cumulates these results. ${ }^{2}$

The fixed-base Törnqvist does not equal the chained Törnqvist in general, and for our sample of weekly tuna data, we find that the difference between these two indexes is rather large: the chained Törnqvist has a pronounced upward bias for most regions of the United States. ${ }^{3}$ The reason for this is that periods of low price (i.e., sales) attract high purchases only when they are accompanied by advertising, and this tends to occur in the final weeks of a sale. Thus, the initial price decline, when the sale starts, does not receive as much weight in the cumulative index as the final price increase, when the sale ends. The demand behavior that leads to this upward bias of the chained Törnqvist - with higher purchases at the end of a sale - means that consumers are very likely purchasing goods for inventory accumulation. The only theoretically correct index to use in this type of situation is a fixed-base index, as demonstrated in section 5.3. Thus, our empirical results reinforce our theoretical results in showing the validity of fixed-base indexes when using high-frequency data.

In section 5.6, we directly investigate the extent to which the weekly purchases of tuna are consistent with inventory behavior. We find some statistical support for this hypothesis, more so in the Northern regions of the United States than in the South. We also find that advertising and special displays have a very pronounced impact on shopping patterns. Concluding remarks are given in section 5.7.

\subsection{A Representative Consumer Model}

The purchases of consumers from a retail outlet, as distinct from their consumption, have been modeled in a "household production" framework by Betancourt and Gautschi (1992). They have in mind any number of reasons why purchases differ from consumption, for example, because the individual must spend time to transform the former to the latter. Here we focus on the intertemporal decisions of a consumer purchasing a storable

2. Since Cobb-Douglas utility, which underlies the Geometric formula, implies constant expenditure shares, we do not compute a chained Geometric index.

3. An upward bias of the chained index with high-frequency data has also been noted by Triplett (1999, and also chapter 6 of this volume). 
good, so that purchases and consumption differ due to inventory behavior. With this simplification, we initially summarize the two-stage decision problem presented by Betancourt and Gautschi and then show how even sharper results can be obtained by considering a single-stage decision problem.

Suppose the consumer is making the purchases $q_{t}$ of a single brand of tuna, over the planning horizon $t=1, \ldots, T$. Consumption of tuna over the same horizon is denoted by $x_{t}$, and the vectors of purchases and consumption are $\mathbf{q}=\left(q_{1}, \ldots, q_{T}\right)$ and $\mathbf{x}=\left(x_{1}, \ldots, x_{T}\right)$. Purchases and consumption are related; for example, we might specify that the sums of each over the horizon are equal. This would not allow for the decay of items (e.g., losing them), or any other reason that the consumer might limit purchases even when the item is on sale. We capture the general relationship between purchases and consumption by the constraints $f(\mathbf{q}, \mathbf{x})<0$, where $f$ is a vector of quasi-convex functions. Given consumption $\mathbf{x}$, the individual then solves the first-stage problem:

$$
\min _{\mathbf{q} \geq 0} \sum_{t=1}^{T} p_{t} q_{t} \text { subject to } f(\mathbf{q}, \mathbf{x}) \leq 0,
$$

where the price of the item in period $t$ is $p_{t}$, and the vector of prices is $\mathbf{p}=$ $\left(p_{1}, \ldots, p_{T}\right)$. It is assumed that consumers know the future prices with perfect foresight. The constraint set represented by $f(\mathbf{q}, \mathbf{x})<0$ includes the feasibility constraints (e.g., that time $t$ consumption cannot exceed time $t$ purchases plus storage), the effect of depreciation during storage, and so on.

Denote the solution to equation (1) as the $\operatorname{costs} C(\mathbf{p}, \mathbf{x})$. As usual, the derivative of this cost function with respect to prices gives the optimal level of purchases, $\mathbf{q}^{*}=C_{p}(\mathbf{p}, \mathbf{x})$. In the second stage, the consumer maximizes utility subject to the constraint that these costs do not exceed the available income $I$ :

$$
\max _{\mathbf{q} \geq 0} U(\mathbf{x}, \mathbf{z}) \text { subject to } C(\mathbf{p}, \mathbf{x}) \leq I,
$$

where $\mathbf{z}=\left(z_{1}, \ldots, z_{N}\right)$ is a vector of consumption of all other goods, which we take as exogenous. ${ }^{4}$ When $N$ is chosen suitably large, this vector can include all goods that complement or substitute for canned tuna in all periods. Let us denote the optimal level of consumption obtained from equation (2) as $\mathbf{x}^{*}=g(\mathbf{p}, \mathbf{z}, I)$. Then it follows that optimal purchases can be obtained as $\mathbf{q}^{*}=C_{p}[\mathbf{p}, g(\mathbf{p}, \mathbf{z}, I)]$. This slightly complex formula for purchases does not show their relation to underlying utility, however, so we now consider a simpler derivation.

Consider combining equations (1) and (2) into a single-stage problem:

$$
\min _{\mathbf{q}, \mathbf{x} \geq 0} \sum_{t=1}^{T} p_{t} q_{t} \text { subject to } f(\mathbf{q}, \mathbf{x}) \leq 0 \text { and } U(\mathbf{x}, \mathbf{z}) \geq \bar{U},
$$

4. Note that income $I$ is net of the cost of purchasing the goods $z$. 
where $\bar{U}$ is an exogenous level of utility. We can write the solution to equation (3) as an expenditure function, $E(\mathbf{p}, \mathbf{z}, \bar{U})$. Differentiating this function with respect to prices, and using the envelope theorem, we obtain optimal purchases $\mathbf{q}^{*}=E_{p}(\mathbf{p}, \mathbf{z}, \bar{U})$. These must equal purchases computed from our two-stage results above, so that $E_{p}(\mathbf{p}, \mathbf{z}, \bar{U})=C_{p}[\mathbf{p}, g(\mathbf{p}, \mathbf{z}, E(\mathbf{p}, \mathbf{z}, \bar{U}))]$. Clearly, the single-stage problem gives a much simpler expression. In particular, the derivatives of the expenditure function are fully observable since they equal purchases rather than consumption. We might expect, therefore, that this information will be enough to "work back" and reveal enough properties of the expenditure function itself so as to construct a COL index - that is, that it will be valid to use the price and quantity of purchases to construct a COL index, representing the expenditures needed to achieve utility $\bar{U}$ at various prices. This type of result has been argued by Diewert (2000, section 9), using a household time-allocation model of Becker. We now show that this result holds in our model above, using some well-known propositions from the price index literature.

Let $\tau=0,1$ denote two planning horizons, each of length $T$ periods. For concreteness, we can say that the periods $t$ denote weeks, and the planning horizons $\tau=0,1$ are years. We then consider the problem of a consumer's making weekly purchases in one year as compared to another. This formulation ignores the issue that at the end of the first year, the optimal purchases should depend on the prices in the beginning of the next year; by treating the two planning horizons as distinct, we are supposing that there is no overlap in the information used by the consumer to make decisions in one year versus the next. This is a simplification.

The price vectors $\mathbf{p}^{\tau}$ differ across the years, as do the exogenous variables $\mathbf{z}^{\tau}$ and the level of annual utility $U^{\tau}$. We will specify that the expenditure function in year $\tau, E\left(\mathbf{p}^{\tau}, \mathbf{z}^{\tau}, U^{\tau}\right)$, takes on a translog functional form over its price arguments:

$$
\ln E=\alpha_{0}^{\tau}+\sum_{t=1}^{T} \alpha_{t}^{\tau} \ln p_{t}^{\tau}+\frac{1}{2} \sum_{s=1}^{T} \sum_{t=1}^{T} \gamma_{s t} \ln p_{s}^{\tau} \ln p_{t}^{\tau}
$$

where

$$
\alpha_{t}^{\tau}=h_{t}\left(\mathbf{z}^{\tau}, U^{\tau}\right), \quad t=0,1, \ldots, T .
$$

Without loss of generality we can suppose that $\gamma_{s t}=\gamma_{t s}$ in equation (4). The functions $h_{t}\left(\mathbf{z}^{\tau}, u^{\tau}\right)$ in equation (5) are left unspecified, except for the requirement that the translog function is linearly homogeneous in prices, which is satisfied if

$$
\sum_{t=1}^{T} \alpha_{t}^{\tau}=1 \text { and } \sum_{t=1}^{T} \gamma_{s t}=\sum_{t=1}^{T} \gamma_{t s}=0 .
$$

The first condition implies that the functions must sum to unity over $t=$ $1, \ldots, T$, for $\tau=0,1$. Additional properties on these functions can be 
imposed to ensure that the expenditure function is increasing in utility and to obtain any desired properties with respect to the exogenous variables $\mathbf{z}^{\tau}$.

The formulation in equations (4)-(6) is quite general, and it is well known that the translog function provides a second-order approximation to an arbitrary function around a point (Diewert 1976). The form in which we have written the expenditure function emphasizes that changes in the exogenous variables $\mathbf{z}^{\tau}$ and $U^{\tau}$ in equation (5) act as shift parameters to the function in equation (4). For example, changes in the value of the function $\alpha_{0}^{\tau}=h_{0}\left(\mathbf{z}^{\tau}\right.$, $U^{\tau}$ ) have a neutral impact on the expenditure function in equation (4). More importantly, changes in value of $\alpha_{t}^{\tau}$, for $t=1, \ldots, T$, have a nonneutral impact on the expenditure function in equation (4). The importance of this can be seen by differentiating the log of expenditure with respect to the log of prices $\mathbf{p}^{\tau}$, obtaining the share of annual expenditures spent on tuna in each week:

$$
s_{t}^{\tau} \equiv \frac{p_{t}^{\tau} q_{t}^{\tau}}{\sum_{t=1}^{T} p_{t}^{\tau} q_{t}^{\tau}}=\alpha_{t}^{\tau}+\sum_{s=1}^{T} \gamma_{s t} \ln p_{s}^{\tau} .
$$

Thus, changes in annual utility or in the exogenous variables $\mathbf{z}^{\tau}$, which affect $\alpha_{t}^{\tau}$, clearly have an impact on the share of expenditure spent on tuna each period. For example, the consumption of more beef might shift demand away from tuna in some periods. Seasonal effects on demand are incorporated also, because $\alpha_{t}^{\tau}$ can change exogenously over time. ${ }^{5}$ In summary, the expenditure function in equations (4)-(6) encompasses a very wide range of demand behavior, across both products and time within the planning horizon.

We next need to specify how to measure the COL. Normally, the COL index is measured as the ratio of expenditure needed to obtain a fixed level of utility at two different prices. In our application, we have the utility levels $U^{0}$ and $U^{1}$ in the two years, so which should we choose? We follow Caves, Christensen, and Diewert (1982a,b) in considering a geometric mean of the ratio of expenditure levels needed to obtain each level of utility:

$$
\mathrm{COL} \equiv\left[\frac{E\left(\mathbf{p}^{1}, \mathbf{z}^{1}, U^{1}\right)}{E\left(\mathbf{p}^{0}, \mathbf{z}^{1}, U^{1}\right)} \frac{E\left(\mathbf{p}^{1}, \mathbf{z}^{0}, U^{0}\right)}{E\left(\mathbf{p}^{0}, \mathbf{z}^{0}, U^{0}\right)}\right]^{1 / 2} .
$$

The first term on the right of equation (8) gives the ratio of annual expenditures need to obtain utility $U^{1}$, holding fixed the exogenous variable $\mathbf{z}^{1}$ but with prices changing. Of course, the consumer does not actually face the

5. Seasonal effects in tuna purchases are found by Chevalier, Kashyap, and Rossi (2000). By constructing the price index over the entire planning horizon, we are comparing one entire year of seasons with the next. This corresponds to the annual index, which compares a moving total of twelve months with twelve base year months, that has been proposed by Diewert (1999) to properly handle seasonal effects. 
prices $\mathbf{p}^{0}$ with exogenous variables $\mathbf{z}^{1}$, so the expenditure level $E\left(\mathbf{p}^{0}, \mathbf{z}^{1}, U^{1}\right)$ is not observed. Similarly, the second term on the right side of equation (8) gives the ratio of annual expenditures needed to obtain utility $U^{0}$, holding fixed the exogenous variable $\mathbf{z}^{0}$ and with prices changing. Again, the expenditure $E\left(\mathbf{p}^{1}, \mathbf{z}^{0}, U^{0}\right)$ is not observed.

Despite the fact that equation (8) consists partially of unobserved information, this geometric mean can indeed be measured with data on purchases and prices:

THEOREM (Caves, Christensen, and Diewert): If the annual expenditure function takes the form in equations (4)-(6), and purchases are optimally chosen so that equation (7) holds, then the COL in equation (8) can be computed as a Törnqvist index:

$$
\mathrm{COL}=\exp \left[\sum_{t=1}^{T} \frac{1}{2}\left(s_{t}^{0}+s_{t}^{1}\right) \ln \left(\frac{p_{t}^{1}}{p_{t}^{0}}\right)\right] .
$$

We provide a brief proof in the appendix. This result of Caves, Christensen, and Diewert (1982a,b) demonstrates the generality of the Törnqvist index, in that it accurately measures the COL even when the "first-order" parameters $\alpha_{t}^{\tau}$ of the translog function are changing. In a producer context, such changes capture nonneutral technical change, whereas in our consumer context these changes can capture change in prices of exogenous commodities, seasonal effects, and even the effects of advertising if it shifts $\alpha_{t}^{\tau}$.

Although our results so far were obtained for a single variety of tuna, purchased over time, they readily extend to multiple varieties. Thus, suppose that the price vectors $\mathbf{p}^{0}$ and $\mathbf{p}^{1}$ in equation (8) include the prices of $i=$ $1, \ldots, N$ varieties over $t=1, \ldots, T$ periods. Then the COL is still measured with a Törnqvist index, defined over varieties and time:

$$
\mathrm{COL}=\exp \left[\sum_{t=1}^{T} \sum_{i=1}^{N} \frac{1}{2}\left(s_{i t}^{0}+s_{i t}^{1}\right) \ln \left(\frac{p_{i t}^{1}}{p_{i t}^{0}}\right)\right],
$$

where the expenditure shares are $s_{i t}^{\tau} \equiv p_{i t}^{\tau} q_{i t}^{\tau} / \sum_{t=1}^{T} \sum_{i=1}^{N} p_{i t}^{\tau} q_{i t}^{\tau}$. We shall refer to equation (10) as the "true" COL index, and contrast it with various other formulas traditionally used by the BLS. In order to implement any of these formulas, we need to decide what to use as the base period, when $\tau=0$. We will be interested in focusing on the effects of sales on consumer purchases, so we will choose the base period prices as the mode prices for each item in an initial year (i.e., the typical nonsale prices). Correspondingly, the expenditure share in the base period will be constructed using the average quantity at the modal price. It follows that our base period prices and expenditure shares will not differ over weeks, so we rewrite these as $p_{i 0}$ and $s_{i 0}$. Then we can also drop the superscript " 1 " for the current year and rewrite equation (10) simply as 


$$
\mathrm{COL}=\exp \left[\sum_{t=1}^{T} \sum_{i=1}^{N} \frac{1}{2}\left(s_{i 0}+s_{i t}\right) \ln \left(\frac{p_{i t}}{p_{i 0}}\right)\right] .
$$

In the next section, we use summary statistics to begin to investigate the frequency of sales and advertising in the data for canned tuna and the extent to which these affect demand. Price indexes are constructed in section 5.4 , where we contrast equation $\left(10^{\prime}\right)$ with alternative formulas. Finally, in section 5.5 we directly test for the influence of inventory behavior on demand.

\subsection{Tuna Data}

The data we shall use are taken from the ACNielsen academic database. They include two years (1992-93) of weekly data, for 316 Universal Product Codes (UPCs) of canned tuna. There are ten market areas, with a total of 690 stores; the smallest market area is the Southwest (54 stores) and the largest is the Northeast ( 86 stores). The data are drawn from a random sample of the large-scale ACNielsen ScanTrack database. For each store, UPC product, and week, the database includes the value of sales, the quantity sold, and a host of marketing indicators. These indicators can be broken into two groups: advertising indicators (regarding whether there was a sale and what type of ads were used) and display indicators (regarding whether the product appeared in a special location within the store).

An example of the data for two actual products sold in one store, over the first six months of 1993, is shown in table 5.1. We define the "typical" price for a product as the mode price in each year, which was $66 \notin$ for product A and $\$ 1.29$ for product B in 1993, as indicated at the bottom of table 5.1. Both of these mode prices had fallen from the year before. We further define a "sale" as a week whose (average) price is at least 5 percent less than the annual mode price. The occurrences of sales are indicated in bold in table 5.1. In some cases, a sale coincides with an advertisement for the product, ${ }^{6}$ and these cases are shown in italics. Notice that for both products, there are several instances in which the product first goes on sale without an advertisement, in which case the quantity does not increase by much, if at all. Following this, an ad occurs at the end of the sale, and this leads to a very marked increase in the quantity purchased. This particular pattern of purchases - which has a large increase at the end of the sale - is consistent with inventory behavior. When it occurs simultaneously with an ad, however, we will need to try to distinguish whether the behavior arises due to advance purchase and storage, or due to the information that consumers receive from the ad.

6. There are five different kinds of advertisements indicated in the database, such as featured ads, ads with coupons, etc., but we do not distinguish them. Similarly, there are a number of different kinds of displays, but we do not distinguish these in our analysis. 
Table 5.1

Data for Two Sample Products, January-June 1993

\begin{tabular}{|c|c|c|c|c|c|c|}
\hline \multirow[b]{2}{*}{ Week Ending: } & \multicolumn{3}{|c|}{ Product A } & \multicolumn{3}{|c|}{ Product B } \\
\hline & Quantity & Price & $\mathrm{Ad}$ & Quantity & Price & $\mathrm{Ad}$ \\
\hline $1 / 09 / 93$ & 25 & 0.66 & $\mathrm{~N}$ & 15 & 1.39 & $\mathrm{~N}$ \\
\hline $1 / 16 / 93$ & 17 & 0.66 & $\mathrm{~N}$ & 20 & 1.29 & $\mathrm{~N}$ \\
\hline $1 / 23 / 93$ & 150 & 0.59 & $Y$ & 14 & 1.29 & $\mathrm{~N}$ \\
\hline $1 / 30 / 93$ & 109 & 0.59 & $Y$ & 24 & 1.29 & $\mathrm{~N}$ \\
\hline $2 / 06 / 93$ & 58 & 0.66 & $\mathrm{~N}$ & 31 & 1.29 & $\mathrm{~N}$ \\
\hline $2 / 13 / 93$ & 38 & 0.66 & $\mathrm{~N}$ & 16 & 1.29 & $\mathrm{~N}$ \\
\hline $2 / 20 / 93$ & 7 & 0.33 & $\mathbf{N}$ & 8 & 1.29 & $\mathrm{~N}$ \\
\hline $2 / 27 / 93$ & 5 & 0.33 & $\mathbf{N}$ & 15 & 1.19 & $\mathbf{N}$ \\
\hline 3/06/93 & 213 & 0.49 & $Y$ & 21 & 1.19 & $\mathbf{N}$ \\
\hline $3 / 13 / 93$ & 43 & 0.66 & $\mathrm{~N}$ & 92 & 1.19 & $Y$ \\
\hline $3 / 20 / 93$ & 12 & 0.66 & $\mathrm{~N}$ & 19 & 1.29 & $\mathrm{~N}$ \\
\hline $3 / 27 / 93$ & 5 & 0.33 & $\mathbf{N}$ & 27 & 1.29 & $\mathrm{~N}$ \\
\hline $4 / 03 / 93$ & 50 & 0.66 & $\mathrm{~N}$ & 23 & 1.29 & $\mathrm{~N}$ \\
\hline $4 / 10 / 93$ & 231 & 0.49 & $Y$ & 22 & 1.29 & $\mathrm{~N}$ \\
\hline $4 / 17 / 93$ & 15 & 0.66 & $\mathrm{~N}$ & 15 & 1.29 & $\mathrm{~N}$ \\
\hline 4/24/93 & 18 & 0.66 & $\mathrm{~N}$ & 28 & 1.39 & $\mathrm{~N}$ \\
\hline $5 / 01 / 93$ & 3 & 0.33 & $\mathbf{N}$ & 12 & 1.39 & $\mathrm{~N}$ \\
\hline $5 / 08 / 93$ & 18 & 0.33 & $\mathbf{N}$ & 8 & 1.39 & $\mathrm{~N}$ \\
\hline $5 / 15 / 93$ & 210 & 0.50 & $Y$ & 11 & 1.39 & $\mathrm{~N}$ \\
\hline $5 / 22 / 93$ & 6 & 0.66 & $\mathrm{~N}$ & 19 & 1.39 & $\mathrm{~N}$ \\
\hline $5 / 29 / 93$ & 21 & 0.66 & $\mathrm{~N}$ & 18 & 1.19 & $\mathbf{N}$ \\
\hline $6 / 05 / 93$ & 15 & 0.66 & $\mathrm{~N}$ & 43 & 1.19 & $\mathbf{N}$ \\
\hline $6 / 12 / 93$ & 29 & 0.66 & $\mathrm{~N}$ & 81 & 1.19 & $Y$ \\
\hline 6/19/93 & 6 & 0.66 & $\mathrm{~N}$ & 13 & 1.39 & $\mathrm{~N}$ \\
\hline $6 / 26 / 93$ & 4 & 0.66 & $\mathrm{~N}$ & 15 & 1.39 & $\mathrm{~N}$ \\
\hline Mode 92 & 20.6 & 0.79 & & 17.7 & 1.39 & \\
\hline Mode 93 & 23.8 & 0.66 & & 19.9 & 1.29 & \\
\hline
\end{tabular}

Notes: Data in bold or in italics are on sale, with price more than 5 percent below the yearly mode. Data in italics also have an advertisement, as tends to occur in the final week of each sale. Demand is exceptionally high in these final weeks when the product is advertised.

In table 5.2 we report summary statistics of the data for three market areas: the Northeast (with eighty-six stores), Midwest (with fifty-seven stores) and Southwest (with fifty-four stores), for 1992 and 1993. All values reported are averaged across the product and stores in each region. First, we report the modal prices for each year, ranging from $\$ 1.30$ (in the Midwest, 1992) to $\$ 1.73$ (in the Northeast, 1993). For each product, we then measure its price each week relative to the mode for the year. Sales are defined as a week in which this "relative price" is less than $0.95 .^{7}$ The average value of

7. Out of 24,284 products in different stores in 1992,86 percent of them had the mode price within one percent of the median price (this calculation gives 84 percent in 1993). Thus, we expect that using the median price rather than the mode price to define sales would lead to similar results. 


\begin{tabular}{|c|c|c|c|c|c|c|}
\hline & \multicolumn{2}{|c|}{ Northeast } & \multicolumn{2}{|c|}{ Midwest } & \multicolumn{2}{|c|}{ Southwest } \\
\hline & 1992 & 1993 & 1992 & 1993 & 1992 & 1993 \\
\hline Mode price (\$) & 1.69 & 1.73 & 1.30 & 1.32 & 1.56 & 1.59 \\
\hline \multicolumn{7}{|l|}{ Relative to mode } \\
\hline Price & 0.988 & 0.986 & 1.005 & 1.000 & 1.000 & 0.989 \\
\hline \multicolumn{7}{|l|}{ During weeks without sales } \\
\hline \multicolumn{7}{|l|}{ No displays or ads } \\
\hline Price & 1.02 & 1.01 & 1.03 & 1.02 & 1.03 & 1.02 \\
\hline Quantity & 0.98 & 0.99 & 0.98 & 0.98 & 0.98 & 0.99 \\
\hline \multicolumn{7}{|l|}{ With display, no ad } \\
\hline Price & 1.02 & 1.02 & 1.02 & 1.03 & 1.04 & 1.04 \\
\hline Quantity & 1.84 & 1.72 & 1.50 & 1.66 & 1.69 & 1.67 \\
\hline \multicolumn{7}{|l|}{ With advertisement } \\
\hline Price & 1.01 & 1.01 & 1.02 & 1.04 & 1.03 & 1.04 \\
\hline Quantity & 2.22 & 1.46 & 2.20 & 2.02 & 1.68 & 1.88 \\
\hline \multicolumn{7}{|l|}{ During weeks with sales } \\
\hline \multicolumn{7}{|l|}{ No displays or ads } \\
\hline Price & 0.85 & 0.87 & 0.88 & 0.89 & 0.87 & 0.87 \\
\hline Quantity & 1.94 & 1.79 & 1.97 & 1.40 & 1.87 & 2.09 \\
\hline \multicolumn{7}{|l|}{ With display, no ad } \\
\hline Price & 0.74 & 0.76 & 0.84 & 0.81 & 0.82 & 0.78 \\
\hline Quantity & 7.20 & 7.94 & 5.93 & 6.41 & 6.77 & 5.64 \\
\hline \multicolumn{7}{|l|}{ With advertisement } \\
\hline Price & 0.66 & 0.68 & 0.76 & 0.75 & 0.73 & 0.70 \\
\hline Quantity & 12.64 & 11.70 & 7.01 & 6.25 & 8.81 & 9.14 \\
\hline Frequency of no sale $(\%)$ & 82.6 & 80.8 & 84.7 & 81.1 & 80.0 & 77.5 \\
\hline Frequency of sales $(\%)$ & 17.4 & 19.2 & 15.3 & 18.9 & 20.1 & 22.5 \\
\hline Lasting one week & 44.9 & 45.2 & 40.1 & 26.0 & 34.4 & 24.9 \\
\hline Lasting two weeks & 19.1 & 15.1 & 16.5 & 15.2 & 22.1 & 15.6 \\
\hline Lasting three weeks & 6.1 & 9.3 & 6.1 & 6.7 & 7.9 & 11.0 \\
\hline Lasting four weeks & 5.6 & 9.6 & 7.0 & 9.2 & 7.5 & 15.6 \\
\hline More than four weeks & 24.4 & 21.0 & 30.4 & 43.0 & 28.2 & 33.0 \\
\hline \multicolumn{7}{|l|}{ During weeks without sales } \\
\hline Freq. of no displays or ads ( $\%)$ & 98.4 & 98.7 & 96.9 & 97.2 & 97.6 & 98.7 \\
\hline Freq. of displays, not ads (\%) & 1.0 & 0.8 & 2.2 & 2.1 & 1.3 & 0.9 \\
\hline Freq. of advertisements $(\%)$ & 0.6 & 0.5 & 0.9 & 0.7 & 1.2 & 0.4 \\
\hline \multicolumn{7}{|l|}{ During weeks with sales } \\
\hline Freq. of no displays or ads $(\%)$ & 78.2 & 80.7 & 81.6 & 86.9 & 81.0 & 85.2 \\
\hline Freq. of displays, not ads (\%) & 3.4 & 2.9 & 7.0 & 5.3 & 2.6 & 1.9 \\
\hline Freq. of advertisements (\%) & 18.4 & 16.4 & 11.3 & 7.8 & 16.4 & 12.9 \\
\hline \multicolumn{7}{|l|}{ Freq. of ads during sales $(\%)$} \\
\hline For sales of one week only & 71.7 & 65.1 & 56.9 & 62.1 & 59.7 & 67.4 \\
\hline At start (for sales > one week) & 26.4 & 16.1 & 10.6 & 5.9 & 27.2 & 11.2 \\
\hline At end (for sales $>$ one week) & 19.2 & 14.4 & 20.4 & 18.1 & 24.1 & 18.1 \\
\hline
\end{tabular}


this relative price and the unit value (constructed as the sales-weighted average of the relative prices) are reported in the second and third rows. Naturally, the unit values are below the average relative prices, indicating that consumers purchase more when prices are low. Following this, we report average prices (relative to the mode) and quantities (relative to the mean quantity at the mode price), during weeks with and without sales. Three cases are distinguished: (i) no display or ad; (ii) a display but no ad; (iii) an advertisement (with or without a special display).

In weeks without sales, having either a display or an advertisement is seen to increase the quantity purchased by 1.5 to 2 times. Surprisingly, about the same impact is obtained from having a sale in the absence of both displays and ads. Larger impacts are obtained when either of these features accompanies a sale, and the combination of a sale and advertisement increases the quantity purchased by six to thirteen times. Generally, sales occur in 15-23 percent of the weeks, and of these, somewhere between one-quarter and one-half of the sales last only one week or last more than four weeks. Less than 1 percent of weeks without sales have ads, but 8-18 percent of the weeks with sales also have ads. At the bottom of table 5.2 we report the frequency of such ads during sales: for sales lasting only one week, 57-67 percent have ads; for sales lasting longer, 6-27 percent have an ad in the first week, and 14-24 percent have an ad in the last week. In the Midwest, we are much more likely to see an ad at the end of a sale than at the beginning, but the reverse holds in the Northeast, and there is no consistent pattern in the Southwest.

\subsection{Formulas for Price Indexes}

The individual tuna varieties (i.e., UPC codes) are denoted by the subscript $i$ within each store. We will be using the modal price in 1992 as a "base period" price $p_{i 0}$, and let $q_{i 0}$ denote the mean quantity purchased at that price in 1992. Then the Laspeyres index from the base period to the week $t$ in 1993 is

$$
P_{t}^{L} \equiv \frac{\sum_{i} q_{i 0} p_{i t}}{\sum_{i} q_{i 0} p_{i 0}}=\sum_{i} w_{i 0}\left(\frac{p_{i t}}{p_{i 0}}\right),
$$

where the equality in equation (11) follows by defining the base period expenditure shares, $w_{i 0} \equiv p_{i 0} q_{i 0} / \sum_{i} p_{i 0} q_{i 0}$.

We will refer to equation (11) as a fixed-base Laspeyres index. It can be distinguished from the chained Laspeyres, which is constructed by first taking the week-to-week index,

$$
P_{t-1, t}^{L} \equiv \sum_{i} w_{i 0}\left(\frac{p_{i t}}{p_{i t-1}}\right),
$$


using the same base period weights. The chained Laspeyres is then constructed by simply cumulating these week-to-week indexes:

$$
C P_{t}^{L} \equiv C P_{t-1}^{L} \cdot P_{t-1, t}^{L}, \quad \text { with } C P_{0}^{L} \equiv 1 .
$$

It is well known that the chained Laspeyres has an upward bias, because it does not satisfy the "time reversal" test. ${ }^{8}$ For this reason BLS generally uses fixed-base formulas, constructed over the "long-term relatives" $p_{i t} / p_{i 0}$. We will be constructing the chained Laspeyres for comparison purposes. ${ }^{9}$

An alternative to using the arithmetic mean in equation (11) is to use a weighted geometric mean of the prices for individual products. This results in the fixed-base Geometric index,

$$
P_{t}^{G}=\exp \left[\sum_{i} w_{i 0} \ln \left(\frac{p_{i t}}{p_{i 0}}\right)\right] .
$$

Note that the fixed-base Geometric formula in equation (14) would be identical to a chained version (constructed by defining a week-to-week geometric index $P_{t-1, t}^{G}$ and then cumulating). For this reason, we do not construct the chained Geometric.

The Laspeyres and Geometric indexes presume, respectively, zero and unit elasticity of substitution among varieties. To provide a better approximation to changes in the COL under more general assumption, we consider the superlative Törnqvist functional form. The fixed-based Törnqvist index is defined as

$$
P_{t}^{T}=\exp \left[\sum_{i} \frac{1}{2}\left(w_{i 0}+w_{i t}\right) \ln \left(\frac{p_{i t}}{p_{i 0}}\right)\right],
$$

where $w_{i t} \equiv p_{i t} q_{i t} / \sum_{i \in I_{k}} p_{i t} q_{i t}$ is the expenditure share of product $i$ in week $t .^{10}$ It is important to compare this formula to the true COL index in equation $\left(10^{\prime}\right)$, which is also a Törnqvist formula: the only difference is that equation $\left(10^{\prime}\right)$ is aggregated over varieties and time, whereas equation (15) is aggregated only over varieties, for a single week. If we average equation (15) over all the weeks in a year, then we would expect the result to be quite close to that calculated from equation $\left(10^{\prime}\right) .{ }^{11}$ Thus, an average of the Törnqvist in-

8. Denoting any price index by $P\left(\mathbf{p}_{t-1}, \mathbf{p}_{t}\right)$, the "time reversal" test is satisfied if $P\left(\mathbf{p}_{t-1}, \mathbf{p}_{t}\right) P\left(\mathbf{p}_{t}\right.$, $\left.\mathbf{p}_{t-1}\right)=1$. That is, when prices change from $\mathbf{p}_{t-1}$ to $\mathbf{p}_{t}$ and then back to $\mathbf{p}_{t-1}$, we want the twoperiod chained index to be unity. However, this test is not satisfied for the Laspeyres formula in equation (12): it can be shown that $P^{L}\left(\mathbf{p}_{t-1}, \mathbf{p}_{t}\right) P^{L}\left(\mathbf{p}_{t}, \mathbf{p}_{t-1}\right) \geq 1$, so the index is upward biased.

9. An alternative formula for the chained Laspeyres would be to use the period $t-1$ weights in equation (12), so it becomes $\Sigma_{i} w_{i t-1}\left(\mathbf{p}_{i t} / \mathbf{p}_{i t-1}\right)$, which would then be cumulated as in equation (13). Results for this index are reported in note 13.

10. Note that the fixed-base formula does include current data in the expenditure weight.

11. There is not an exact equality between taking a weighted average of (15) over all weeks in the year, versus computing $\left(10^{\prime}\right)$ directly, because calculating a Törnqvist index in two stages is not the same as calculating it directly in one stage. This is shown by Diewert (1978), who nevertheless argues that "approximate" consistency between one-stage and two-stage Törnqvist indexes will obtain. 
dexes in equation (15) appears to be quite close to the true COL index in equation $\left(10^{\prime}\right)$.

An alternative formulation of the Törnqvist is to first construct it on a week-to-week basis:

$$
P_{t-1, t}^{T}=\exp \left[\sum_{i} \frac{1}{2}\left(w_{i t}+w_{i t-1}\right) \ln \left(\frac{p_{i t}}{p_{i t-1}}\right)\right]
$$

The chained Törnqvist is then obtained by cumulating equation (16):

$$
C P_{t}^{T} \equiv C P_{t-1}^{T} \cdot P_{t-1, t}^{T}, \quad \text { with } C P_{0}^{T} \equiv 1 .
$$

The chained Törnqvist in equation (17) will generally not equal the fixedbase Törnqvist in equation (15), and, therefore, we expect that the average values of the chained Törnqvist over a year might differ substantially from the exact index in equation $\left(10^{\prime}\right)$. Thus, we do not have the same justification for equation (17) as for the fixed-base index in equation (15), which we expect to be close to equation $\left(10^{\prime}\right) .^{12}$

\subsection{Calculation of Price Indexes}

We calculated the Laspeyres-ratio, Geometric, and Törnqvist indexes for 1993, using as the base period the mode price in 1992 and the average sales at that price. As an initial example, we show this calculation for the sample data over January-June 1993 in table 5.1, with results in table 5.3. Any of the fixed-base indexes have nearly the same values in the first week of January and last week of June, because the prices for the two products were identical in those weeks (66 for product A and $\$ 1.29$ for product B, respectively). The chained indexes, however, do not satisfy this property. The chained Laspeyres ends up with a value of 1.28 , rising some 37 percent from its value in the first week of January. This is entirely due to the fact that the Laspeyres index does not satisfy "time reversal," so that when one product goes on sale and its price falls temporarily, the index does not return to its former value when the sale ends.

More surprisingly, the chained Törnqvist index shows an even greater upward bias, ending with a value of 1.45 , which is nearly twice the value of the chained Laspeyres! The chained Törnqvist index does satisfy "time reversal" provided that the weekly expenditures are consistent with the maximization of a static (i.e., weekly) utility function. However, this assumption is violated in the data for these two sample products: in periods when the prices are low, but there are no advertisements, the quantities are not high (see table 5.1). Because the ads occur in the final period of the sales, the

12. Alterman, Diewert, and Feenstra (2000, chap. 4, Propositions 1,2) have identified some conditions under which a fixed-base Törnqvist index between two dates, and the chained index between the same dates, will be similar in magnitude. Since these indexes do not coincide in our data, the conditions they identify are not satisfied. 
Table 5.3 Price Indexes Constructed over Two Sample Products, January-June 1993

\begin{tabular}{|c|c|c|c|c|c|}
\hline $\begin{array}{l}\text { Week } \\
\text { Ending }\end{array}$ & $\begin{array}{c}\text { Fixed-Base } \\
\text { Laspeyres }\end{array}$ & $\begin{array}{l}\text { Chained } \\
\text { Laspeyres }\end{array}$ & $\begin{array}{l}\text { Fixed-Base } \\
\text { Geometric }\end{array}$ & $\begin{array}{c}\text { Fixed-Base } \\
\text { Törnqvist }\end{array}$ & $\begin{array}{l}\text { Chained } \\
\text { Törnqvist }\end{array}$ \\
\hline $1 / 09 / 93$ & 0.934 & 0.934 & 0.931 & 0.927 & 0.927 \\
\hline $1 / 16 / 93$ & 0.891 & 0.894 & 0.890 & 0.894 & 0.885 \\
\hline $1 / 23 / 93$ & 0.856 & 0.856 & 0.851 & 0.812 & 0.830 \\
\hline $1 / 30 / 93$ & 0.856 & 0.856 & 0.851 & 0.826 & 0.830 \\
\hline 2/06/93 & 0.891 & 0.897 & 0.890 & 0.886 & 0.886 \\
\hline 2/13/93 & 0.891 & 0.897 & 0.890 & 0.883 & 0.886 \\
\hline $2 / 20 / 93$ & 0.724 & 0.718 & 0.675 & 0.736 & 0.688 \\
\hline $2 / 27 / 93$ & 0.681 & 0.684 & 0.643 & 0.720 & 0.641 \\
\hline $3 / 06 / 93$ & 0.764 & 0.821 & 0.756 & 0.709 & 0.769 \\
\hline $3 / 13 / 93$ & 0.848 & 0.930 & 0.848 & 0.850 & 0.889 \\
\hline $3 / 20 / 93$ & 0.891 & 0.977 & 0.890 & 0.897 & 0.947 \\
\hline $3 / 27 / 93$ & 0.724 & 0.782 & 0.675 & 0.777 & 0.856 \\
\hline $4 / 03 / 93$ & 0.891 & 1.094 & 0.890 & 0.884 & 1.044 \\
\hline 4/10/93 & 0.805 & 0.982 & 0.790 & 0.729 & 0.857 \\
\hline 4/17/93 & 0.891 & 1.118 & 0.890 & 0.893 & 1.015 \\
\hline $4 / 24 / 93$ & 0.934 & 1.170 & 0.931 & 0.945 & 1.071 \\
\hline $5 / 01 / 93$ & 0.768 & 0.936 & 0.706 & 0.820 & 0.968 \\
\hline $5 / 08 / 93$ & 0.768 & 0.936 & 0.706 & 0.722 & 0.968 \\
\hline $5 / 15 / 93$ & 0.851 & 1.123 & 0.830 & 0.743 & 1.240 \\
\hline $5 / 22 / 93$ & 0.934 & 1.272 & 0.931 & 0.954 & 1.433 \\
\hline $5 / 29 / 93$ & 0.848 & 1.163 & 0.848 & 0.848 & 1.277 \\
\hline $6 / 05 / 93$ & 0.848 & 1.163 & 0.848 & 0.850 & 1.277 \\
\hline $6 / 12 / 93$ & 0.848 & 1.163 & 0.848 & 0.850 & 1.277 \\
\hline $6 / 19 / 93$ & 0.934 & 1.280 & 0.931 & 0.949 & 1.452 \\
\hline $6 / 26 / 93$ & 0.934 & 1.280 & 0.931 & 0.955 & 1.452 \\
\hline \multicolumn{6}{|l|}{ Averages } \\
\hline Base 92 & 0.848 & 0.997 & 0.835 & 0.842 & 1.015 \\
\hline Base 93 & 0.951 & 1.116 & 0.941 & 0.946 & 1.144 \\
\hline
\end{tabular}

Notes: Data are for the two products in table 5.1. Data in bold or in italics had one product on sale, with price more than 5 percent below the yearly mode. Data in italics also have an advertisement for that produce, as tends to occur in the final week of each sale. Demand is high in these final weeks when the product is advertised, so the largest increases in the indexesespecially the chained indexes - follow these weeks.

price increases following the sales receive much greater weight than the price decreases at the beginning of each sale. This leads to the dramatic upward bias of the chained Törnqvist. When averaged over all the weeks, the chained Törnqvist gives a value of 1.015 relative to the 1992 modal prices and 1.144 relative to the 1993 model prices; both of these are substantially higher than the fixed-base Törnqvist and the other indexes.

The question arises as to whether this is a general feature of the data on canned tuna. To determine this, we report in table 5.4 the values of prices indexes in 1993 computed for each store and then averaged over the weeks in 1993 and over the ten regions of the United States. The prices indexes are computed using either the modal prices in 1992 as the base or the modal 
Price Indexes Constructed over Complete Sample (average values over 1993)

\begin{tabular}{|c|c|c|c|c|c|c|}
\hline & $\begin{array}{l}\text { True COL } \\
\text { Index }\end{array}$ & $\begin{array}{c}\text { Fixed-Base } \\
\text { Laspeyres }\end{array}$ & $\begin{array}{l}\text { Chained } \\
\text { Laspeyres }\end{array}$ & $\begin{array}{l}\text { Fixed-Base } \\
\text { Geometric }\end{array}$ & $\begin{array}{c}\text { Fixed-Base } \\
\text { Törnqvist }\end{array}$ & $\begin{array}{l}\text { Chained } \\
\text { Törnqvist }\end{array}$ \\
\hline \multicolumn{7}{|c|}{ East Northeast } \\
\hline 1992 base & 0.950 & 1.009 & 1.144 & 1.002 & 0.967 & 0.980 \\
\hline 1993 base & 0.940 & 0.991 & 1.127 & 0.987 & 0.959 & 0.986 \\
\hline \multicolumn{7}{|l|}{ Northeast } \\
\hline 1992 base & 0.937 & 0.987 & 1.204 & 0.976 & 0.941 & 1.006 \\
\hline 1993 base & 0.930 & 0.972 & 1.193 & 0.966 & 0.932 & 0.991 \\
\hline \multicolumn{7}{|l|}{ Northwest } \\
\hline 1992 base & 0.921 & 0.995 & 1.184 & 0.978 & 0.940 & 1.075 \\
\hline 1993 base & 0.954 & 1.007 & 1.224 & 0.996 & 0.971 & 1.097 \\
\hline \multicolumn{7}{|c|}{ West Northwest } \\
\hline 1992 base & 0.977 & 1.013 & 1.118 & 1.002 & 0.978 & 0.998 \\
\hline 1993 base & 0.954 & 0.985 & 1.095 & 0.975 & 0.956 & 0.974 \\
\hline \multicolumn{7}{|l|}{ Midwest } \\
\hline 1992 base & 0.970 & 1.004 & 1.145 & 0.998 & 0.972 & 0.956 \\
\hline 1993 base & 0.958 & 0.983 & 1.108 & 0.978 & 0.960 & 0.956 \\
\hline \multicolumn{7}{|c|}{ Upper Midwest } \\
\hline 1992 base & 0.937 & 0.958 & 1.033 & 0.949 & 0.951 & 0.995 \\
\hline 1993 base & 0.985 & 0.999 & 1.081 & 0.997 & 1.000 & 1.037 \\
\hline \multicolumn{7}{|c|}{ South Southeast } \\
\hline 1992 base & 0.949 & 0.972 & 1.036 & 0.965 & 0.955 & 0.993 \\
\hline 1993 base & 0.988 & 1.006 & 1.072 & 1.001 & 0.994 & 1.034 \\
\hline \multicolumn{7}{|c|}{ South Southwest } \\
\hline 1992 base & 0.970 & 1.006 & 1.104 & 0.997 & 0.978 & 0.976 \\
\hline 1993 base & 0.971 & 0.994 & 1.093 & 0.989 & 0.980 & 0.979 \\
\hline \multicolumn{7}{|l|}{ Southeast } \\
\hline 1992 base & 0.985 & 0.989 & 1.017 & 0.985 & 0.978 & 0.972 \\
\hline 1993 base & 1.000 & 1.007 & 1.043 & 1.005 & 0.998 & 0.994 \\
\hline \multicolumn{7}{|l|}{ Southwest } \\
\hline 1992 base & 0.964 & 1.029 & 1.204 & 1.017 & 0.983 & 1.138 \\
\hline 1993 base & 0.945 & 0.998 & 1.192 & 0.991 & 0.961 & 1.123 \\
\hline \multicolumn{7}{|c|}{ Total United States } \\
\hline 1992 base & 0.956 & 0.996 & 1.119 & 0.987 & 0.964 & 1.007 \\
\hline 1993 base & 0.962 & 0.994 & 1.122 & 0.989 & 0.971 & 1.014 \\
\hline
\end{tabular}

prices in 1993. In the first column of table 5.4, we report the true COL index from equation $\left(10^{\prime}\right)$, constructed relative to each base, and averaged over all stores in each region. The values for this index show the drop in the COL (or, conversely, the welfare gains) from having items periodically on sale during 1993. We are interested in comparing this true index to the others, so as to determine their bias.

From table 5.4, we see that the fixed-base Laspeyres is always higher than the true index and that the chained Laspeyres is considerably higher still. ${ }^{13}$

13. When instead we use the alternative formula for the chained Laspeyres, described in note 8 , then the upward bias of the index is much worse. This is because the weight $\mathrm{w}_{\mathrm{t}-1}$ is much higher as the end of the sale than at the beginning, so the price increase at the end of the sale is given a much greater weight than the price decrease at the beginning. (This problem is amelio- 
Both of these are above the chained and fixed-base Törnqvist, respectively. In addition, the chained Törnqvist exceeds its fixed-base counterpart in many regions of the country: the upward bias of the chained Törnqvist is most apparent in the Northwest and Southwest and occurs in seven out of the ten regions (all except the Midwest, South Southwest, and Southeast). On the other hand, the average of the fixed-base Törnqvist over the stores and weeks is quite close to the average of the true COL index over stores in each region. This result was expected, because the COL index itself was a Törnqvist index computed over product varieties and time, as in equation $\left(10^{\prime}\right)$, whereas our fixed-base Törnqvist has been computed over product varieties and then averaged across weeks. Thus, they differ only in their respective weights.

The difficulty with using the true COL index in equation (10') in practice is that it compares one planning horizon (e.g., a year) to another, whereas the BLS may very well need to report price indexes at higher frequency (i.e., monthly). The fixed-base Törnqvist more than meets this requirement, because it constructed at weekly intervals. Furthermore, as we have shown, the average of the fixed-base Törnqvist is empirically quite close to the COL index. These results, therefore, lend support to fixed-base Törnqvist, even when applied to high-frequency scanner data. Conversely, the upward bias of the chained Törnqvist makes it highly inappropriate to use at high frequency, and it appears that this bias is due to inventory behavior. To confirm this, it would be desirable to have some independent evidence on such behavior, as we explore econometrically in the next section.

\subsection{Estimation of Inventory Behavior}

To determine how demand for tuna responds to prices, we need to adopt a specific functional form. The static constant elasticity of substitution (CES) specification of the utility function leads to a demand curve for a variety of tuna, as follows:

$$
x_{i t}=\left(\frac{p_{i t}}{P_{t}}\right)^{-\rho}
$$

where $x_{i t}$ is consumption (relative to some base), $p_{i t}$ is the price of a variety $i$, and $P_{t}$ is the price index for tuna at time $t$.

We have experimented with developing a full-blown model of inventory behavior for consumers, but it quickly gets very complicated. Simple models have the following implications:

rated in the chained Törnqvist, because the weights are averaged over two periods.) For example, this alternative formula for the chained Laspeyres, then averaged over all weeks in 1993 and stores in a region, equals 20.6 for the Northeast, 2.1 for the Midwest, and 3.1 for the Southwest. In one extreme case (a store in the East Northeast), the week-to-week Laspeyres calculated as in note 8 typically exceeds 1.2 , so that the chained Laspeyres rises from unity to $1.2^{52}>10,000$ during the 1993 year! 
1. Consumers buy for future consumption when goods are on sale.

2. Consumers will buy more when the next sale is more distant.

3. If there is a cost of storage, consumers will defer purchases for storage until the last period of the sale.

4. Sales are asymmetric: Consumers might want to sell back some of their inventory when prices are unusually high (a negative sale), but they cannot.

To make this concrete, consider the following formulation. Suppose that there is a per-period storage cost of $s$ units of tuna. This would include depreciation or loss in storage, the shadow price of shelf space in the pantry, and interest. ${ }^{14}$ Suppose that there is a sale - defined as a substantially lower than normal price, perhaps accompanied by an advertisement. The consumer expects the next sale to be $H$ periods in the future. Then a consumer will purchase now to fulfill future demand. The shadow price of consumption $h$ periods ahead for a variety $i$ put into storage at the time of the sale $t$ is $p_{i t}(1+s)^{h}$. Assuming that the cost of storage $(s)$ and that the time to the next sale $(H)$ are not too high, the consumer will purchase sufficient quantity for all future needs until the next sale. Hence, quantity sold at the time of the sale will be

$$
q_{i t}=\sum_{h=0}^{H}\left(\frac{p_{i t}(1+s)^{h}}{P_{t}}\right)^{-\rho}=\left(\frac{p_{i}}{P_{t}}\right)^{-\rho}\left(\frac{1-(1+s)^{-\rho(H+1)}}{1-(1+s)^{-\rho}}\right) .
$$

If the shadow price $p_{i t}(1+s)^{h}$ exceeds some future price $p_{i, t+H^{\prime}}$ prior to the next sale, then the process is truncated at $H^{\prime}$. If $s$ is small, then the term in the power of $H$ simplifies to be simply $(H+1)$ itself, since by L'Hospital's rule:

$$
\lim _{s \rightarrow 0}\left(\frac{1-(1+s)^{-\rho(H+1)}}{1-(1+s)^{-\rho}}\right)=H+1 .
$$

In order to estimate equation (19), we take natural logs and make use of equation (20). We include both current prices and leads and lags up to length $L$, obtaining the estimating equation:

$$
\begin{aligned}
\ln q_{i t}= & \beta_{0}+\sum_{\ell=-L}^{L} \beta_{1 \ell} \ln p_{i t+\ell}+\sum_{\ell=-L}^{L} \beta_{2 \ell} \ln P_{t+\ell}+\beta_{3} \ln \left(1+H_{\text {own }, i t}\right) \\
& +\beta_{4} \ln \left(1+H_{\text {any }, t}\right)+\varepsilon_{i t}
\end{aligned}
$$

where $q_{i t}$ are weekly sales measured relative to the quantity at the mode price; $p_{i t}$ is the price in that week relative to its mode for the year; $P_{t}$ is the fixed-base Törnqvist index for that store; $H_{\text {own, }, t}$ is the number of weeks to the next sale of this product $i$; and $H_{\text {any, } t}$ is the number of weeks to the next

14. There is a problem with units of measurement: depreciation and loss is in units of tuna, whereas interest and storage costs are in units of the numeraire. 
sale in that store of any variety of canned tuna. The inclusion of leads and lags for $p_{i t}$ and $P_{t}$ (up to length $L$ ) allows for intertemporal substitution in consumption, as potentially distinct from inventory behavior. Note that the variables $\ln \left(1+H_{\text {own, } i t}\right)$ and $\ln \left(1+H_{\text {any, } t}\right)$ are nonzero only when it is the last week of a sale; otherwise, they are not relevant to the inventory problem.

Estimates of equation (21) for each region of the United States, over all weeks in 1993, are reported in table 5.5. In the first set of estimates for each region we report the coefficients of equation (21), along with their standard errors. In the second set of estimates, we extend equation (21) to allow for indicator variables indicating whether that variety of tuna had a special display or was advertised, and also an interaction term between advertising and the price of that variety relative to its mode. There are nearly 50,000 observations or more for each region, which pools over weeks, stores, and varieties of tuna. ${ }^{15}$

Estimation is by ordinary least squares, including fixed effects for each store, as recommended by Betancourt and Malanoski (1999). ${ }^{16}$ We do not report the coefficients on the store fixed effects, and we also do not report the coefficients on the lead and lag values of $p_{i t}$ and $P_{t}$. The inclusion of these leads and lag often increased the (absolute) values of the concurrent price elasticities, and the leads and lags themselves were sometimes significant although not always of positive sign. ${ }^{17}$ Most importantly, the inclusion of the leads and lag of prices has little impact on the coefficients on the inventory terms $\ln \left(1+H_{\text {own }, i t}\right)$ and $\ln \left(1+H_{\text {any }, t}\right)$ : the estimates reported in table 5.5 are for a single lead and lag, $L=1$, but similar results are obtained for $L=0$ or $L=2$. Coefficients on $\ln \left(1+H_{\text {own }, t}\right)$ and $\ln \left(1+H_{\text {any }, t}\right)$ that are significantly different from zero at the 5 percent level are indicated in bold.

Strong evidence of inventory behavior is found for the Northeast regions, at the top of table 5.5: the East Northeast has a coefficient of 0.35 on $\ln (1+$ $\left.H_{\text {own }, i t}\right)$, whereas the Northeast has a coefficient of 0.33 on $\ln \left(1+H_{\text {any }, t}\right)$. To interpret these, we can measure the total "inventory effect" on demand during the last week of a sale as

$$
\text { Inventory Effect }=\hat{\beta}_{3} \overline{\ln \left(1+H_{\text {own }, i t}\right)}+\hat{\beta}_{4} \overline{\ln \left(1+H_{\text {own }, i t}\right)} .
$$

Note that the sample average value of $\ln \left(1+H_{\text {own. it }}\right)$ when this variable is positive is 2.4 (so the next sale of each product is 10 weeks away), and the

15. In some cases the value of $H_{\text {own,it }}$ could not be measured, because the next sale of that variety was after the end of the sample, so these observations were omitted. Less frequently, the value of $H_{\text {any }, t}$ could not be measured because the next sale of any variety was after the end of the sample; these values of $H_{\text {any, } t}$ were set equal to zero.

16. We considered using an instrumental variables estimator to take into account less than perfect foresight for $H$, but we obtained inadequate first-stage fits.

17. Betancourt and Gautschi (1992) show generally that for retail purchases (as contrasted with consumption) there is a tendency to obtain complementarity rather than substitution in demand. This might explain the cross-price elasticities that were sometimes significantly negative. 
Table 5.5 Regression Results over 1993 Sample (dependent variable:

Log of quantity [relative to mode])

\begin{tabular}{|c|c|c|c|c|c|c|c|c|}
\hline $\begin{array}{l}\text { Log } \\
\text { Relative Price }\end{array}$ & $\begin{array}{c}\text { Log } \\
\text { Price } \\
\text { Index }\end{array}$ & $\begin{array}{l}\text { Log (Weeks } \\
\text { to Own } \\
\text { Next Sale) }\end{array}$ & $\begin{array}{c}\text { Log (Weeks } \\
\text { to Any } \\
\text { Next Sale) }\end{array}$ & Display & $\mathrm{Ad}$ & $\begin{array}{c}\log \\
\text { Relative } \\
\text { Price } * \text { Ad }\end{array}$ & $R^{2}$ & $N$ \\
\hline \multicolumn{9}{|l|}{ East Northeast } \\
\hline $\begin{array}{c}-3.82 \\
(0.04)\end{array}$ & $\begin{array}{c}0.85 \\
(0.03)\end{array}$ & $\begin{array}{c}0.34 \\
(0.01)\end{array}$ & $\begin{array}{l}-0.08 \\
(0.04)\end{array}$ & & & & 0.23 & 115,434 \\
\hline $\begin{array}{l}-2.25 \\
(0.04)\end{array}$ & $\begin{array}{c}0.84 \\
(0.03)\end{array}$ & $\begin{array}{c}0.11 \\
(0.01)\end{array}$ & $\begin{array}{c}-0.11 \\
(0.04)\end{array}$ & $\begin{array}{l}1.08 \\
(0.02)\end{array}$ & $\begin{array}{c}0.66 \\
(0.02)\end{array}$ & $\begin{array}{l}-1.15 \\
(0.06)\end{array}$ & 0.29 & 115,434 \\
\hline \multicolumn{9}{|l|}{ Northeast } \\
\hline $\begin{array}{l}-3.37 \\
(0.03)\end{array}$ & $\begin{array}{c}0.76 \\
(0.03)\end{array}$ & $\begin{array}{c}0.03 \\
(0.01)\end{array}$ & $\begin{array}{c}0.33 \\
(0.03)\end{array}$ & & & & 0.22 & 120,554 \\
\hline $\begin{array}{l}-2.31 \\
(0.04)\end{array}$ & $\begin{array}{c}0.81 \\
(0.03)\end{array}$ & $\begin{array}{l}-0.01 \\
(0.01)\end{array}$ & $\begin{array}{c}0.22 \\
(0.03)\end{array}$ & $\begin{array}{c}0.71 \\
(0.01)\end{array}$ & $\begin{array}{c}0.46 \\
(0.02)\end{array}$ & $\begin{array}{c}-0.71 \\
(0.06)\end{array}$ & 0.26 & 120,554 \\
\hline \multicolumn{9}{|l|}{ Northwest } \\
\hline $\begin{array}{l}-2.85 \\
(0.04)\end{array}$ & $\begin{array}{c}0.66 \\
(0.04)\end{array}$ & $\begin{array}{c}0.01 \\
(0.02)\end{array}$ & $\begin{array}{c}0.14 \\
(0.04)\end{array}$ & & & & 0.26 & 57,168 \\
\hline $\begin{array}{c}-2.42 \\
(0.05)\end{array}$ & $\begin{array}{c}0.67 \\
(0.04)\end{array}$ & $\begin{array}{c}0.01 \\
(0.02)\end{array}$ & $\begin{array}{c}0.07 \\
(0.04)\end{array}$ & $\begin{array}{c}0.58 \\
(0.03)\end{array}$ & $\begin{array}{c}0.33 \\
(0.02)\end{array}$ & $\begin{array}{c}-0.20 \\
(0.06)\end{array}$ & 0.28 & 57,168 \\
\hline \multicolumn{9}{|l|}{ West Northwest } \\
\hline $\begin{array}{l}-2.57 \\
(0.04)\end{array}$ & $\begin{array}{c}0.79 \\
(0.06)\end{array}$ & $\begin{array}{c}0.01 \\
(0.02)\end{array}$ & $\begin{array}{c}0.05 \\
(0.04)\end{array}$ & & & & 0.15 & 79,488 \\
\hline $\begin{array}{l}-2.32 \\
(0.05)\end{array}$ & $\begin{array}{c}0.85 \\
(0.06)\end{array}$ & $\begin{array}{c}0.01 \\
(0.02)\end{array}$ & $\begin{array}{c}0.04 \\
(0.04)\end{array}$ & $\begin{array}{c}0.57 \\
(0.01)\end{array}$ & $\begin{array}{c}0.41 \\
(0.02)\end{array}$ & $\begin{array}{c}0.34 \\
(0.07)\end{array}$ & 0.18 & 79,488 \\
\hline \multicolumn{9}{|l|}{ Midwest } \\
\hline $\begin{array}{c}-2.26 \\
(0.06)\end{array}$ & $\begin{array}{c}0.56 \\
(0.06)\end{array}$ & $\begin{array}{l}-0.01 \\
(0.03)\end{array}$ & $\begin{array}{c}0.10 \\
(0.05)\end{array}$ & & & & 0.09 & 48,537 \\
\hline $\begin{array}{l}-1.74 \\
(0.07)\end{array}$ & $\begin{array}{c}0.57 \\
(0.06)\end{array}$ & $\begin{array}{l}-0.01 \\
(0.03)\end{array}$ & $\begin{array}{c}0.02 \\
(0.05)\end{array}$ & $\begin{array}{c}0.70 \\
(0.02)\end{array}$ & $\begin{array}{c}0.40 \\
(0.03)\end{array}$ & $\begin{array}{c}-0.10 \\
(0.10)\end{array}$ & 0.13 & 48,537 \\
\hline \multicolumn{9}{|l|}{ Upper Midwest } \\
\hline $\begin{array}{l}-2.21 \\
(0.06)\end{array}$ & $\begin{array}{c}0.38 \\
(0.06)\end{array}$ & $\begin{array}{c}0.15 \\
(0.03)\end{array}$ & $\begin{array}{c}0.19 \\
(0.05)\end{array}$ & & & & 0.08 & 46,906 \\
\hline $\begin{array}{c}-1.34 \\
(0.07)\end{array}$ & $\begin{array}{c}0.48 \\
(0.06)\end{array}$ & $\begin{array}{l}-0.01 \\
(0.03)\end{array}$ & $\begin{array}{c}0.12 \\
(0.05)\end{array}$ & $\begin{array}{c}0.50 \\
(0.02)\end{array}$ & $\begin{array}{c}0.59 \\
(0.03)\end{array}$ & $\begin{array}{l}-1.03 \\
(0.11)\end{array}$ & 0.12 & 46,906 \\
\hline \multicolumn{9}{|l|}{ South Southeast } \\
\hline $\begin{array}{c}-2.04 \\
(0.06)\end{array}$ & $\begin{array}{c}0.40 \\
(0.06)\end{array}$ & $\begin{array}{l}-0.02 \\
(0.03)\end{array}$ & $\begin{array}{c}0.18 \\
(0.05)\end{array}$ & & & & 0.10 & 59,340 \\
\hline $\begin{array}{l}-1.68 \\
(0.07)\end{array}$ & $\begin{array}{c}0.44 \\
(0.06)\end{array}$ & $\begin{array}{c}0.01 \\
(0.03)\end{array}$ & $\begin{array}{l}-0.003 \\
(0.05)\end{array}$ & $\begin{array}{c}0.51 \\
(0.02)\end{array}$ & $\begin{array}{c}0.20 \\
(0.02)\end{array}$ & $\begin{array}{c}-0.71 \\
(0.09)\end{array}$ & 0.11 & 59,340 \\
\hline \multicolumn{9}{|l|}{ Southeast } \\
\hline $\begin{array}{l}-2.06 \\
(0.07)\end{array}$ & $\begin{array}{c}0.27 \\
(0.09)\end{array}$ & $\begin{array}{c}0.09 \\
(0.02)\end{array}$ & $\begin{array}{c}-0.09 \\
(0.04)\end{array}$ & & & & 0.06 & 66,689 \\
\hline $\begin{array}{c}-1.43 \\
(0.08)\end{array}$ & $\begin{array}{c}0.29 \\
(0.09)\end{array}$ & $\begin{array}{c}0.07 \\
(0.02)\end{array}$ & $\begin{array}{c}-0.12 \\
(0.04)\end{array}$ & $\begin{array}{c}0.46 \\
(0.02)\end{array}$ & $\begin{array}{c}0.46 \\
(0.02)\end{array}$ & $\begin{array}{c}-0.27 \\
(0.11)\end{array}$ & 0.08 & 66,689 \\
\hline \multicolumn{9}{|l|}{ Southwest } \\
\hline $\begin{array}{l}-3.26 \\
(0.05)\end{array}$ & $\begin{array}{c}0.62 \\
(0.05)\end{array}$ & $\begin{array}{c}-0.03 \\
(0.02)\end{array}$ & $\begin{array}{c}0.15 \\
(0.05)\end{array}$ & & & & 0.24 & 57,121 \\
\hline $\begin{array}{c}-2.48 \\
(0.05)\end{array}$ & $\begin{array}{c}0.70 \\
(0.05)\end{array}$ & $\begin{array}{c}-0.05 \\
(0.02)\end{array}$ & $\begin{array}{c}0.06 \\
(0.05)\end{array}$ & $\begin{array}{c}0.52 \\
(0.03)\end{array}$ & $\begin{array}{c}0.51 \\
(0.03)\end{array}$ & $\begin{array}{c}-0.62 \\
(0.09)\end{array}$ & 0.26 & 57,121 \\
\hline
\end{tabular}


Table 5.5

(continued)

\begin{tabular}{|c|c|c|c|c|c|c|c|c|}
\hline $\begin{array}{l}\text { Log } \\
\text { Relative Price }\end{array}$ & $\begin{array}{l}\text { Log } \\
\text { Price } \\
\text { Index }\end{array}$ & $\begin{array}{l}\text { Log (Weeks } \\
\text { to Own } \\
\text { Next Sale) }\end{array}$ & $\begin{array}{l}\text { Log (Weeks } \\
\text { to Any } \\
\text { Next Sale) }\end{array}$ & Display & Ad & $\begin{array}{c}\text { Log } \\
\text { Relative } \\
\text { Price } * \text { Ad }\end{array}$ & $R^{2}$ & $N$ \\
\hline \multicolumn{9}{|c|}{ Total United States } \\
\hline $\begin{array}{l}-3.08 \\
(0.01)\end{array}$ & $\begin{array}{c}0.73 \\
(0.01)\end{array}$ & $\begin{array}{l}0.13 \\
(0.006)\end{array}$ & $\begin{array}{c}0.00 \\
(0.01)\end{array}$ & & & & 0.17 & 728,122 \\
\hline $\begin{array}{l}-2.19 \\
(0.02)\end{array}$ & $\begin{array}{c}0.78 \\
(0.01)\end{array}$ & $\begin{array}{l}0.08 \\
(0.006)\end{array}$ & $\begin{array}{c}-0.06 \\
(0.01)\end{array}$ & $\begin{array}{c}0.67 \\
(0.006)\end{array}$ & $\begin{array}{l}0.45 \\
(0.007)\end{array}$ & $\begin{array}{l}-0.78 \\
(0.02)\end{array}$ & 0.20 & 728,122 \\
\hline
\end{tabular}

Notes: Coefficients on weeks to next sale that are significantly different from zero at the 5 percent level are indicated in bold. Standard errors are shown in parentheses. Regressions also included fixed effects by store, and lag and lead prices.

average value of $\ln \left(1+H_{\text {any }, t}\right)$ when this variable is positive is 1.2 (so the next sale of any product is 2.3 weeks away).

Using the coefficients in table 5.5, for the East Northeast the "inventory effect" is $\exp (0.35 * 2.4-0.08 * 1.2)=2.2$, indicating that the quantity demanded during the last week of a sale is more than twice as high as average. For the Northeast region, the "inventory effect" equals $\exp (0.03 * 2.4+$ $0.22 * 1.2)=1.4$, so demand is 40 percent higher at the end of sale. Other regions that show particularly strong inventory behavior are the Upper Midwest, for both inventory variables, and most regions of the South, for the variable reflecting sales in other varieties.

However, when we add the indicator variables for displays and advertising, along with the interaction between advertising and price, then the magnitude of inventory behavior is substantially reduced in all regions. In the cases in which there is still some evidence of inventory behavior - such at the East Northeast and Southeast - a positive coefficient on one of the inventory variables is offset by a negative coefficient on the other. Indeed, when advertising is included then the only region that retains significant evidence of inventory behavior (without an offsetting negative effect) is the Northeast. As an example, in one store in that region a certain tuna product fell in price from $\$ 1.59$ to $88 \&$ in one week and sales went from about 100 cans average to 20,000 in that week! This is the largest demand response in our data set and almost surely indicates that the purchases were for inventory. At the same time, we cannot rule out that some portion of the increased demand was in response to the advertised price of $88 \phi$. Generally, when we take into account displays and advertising in table 5.5, the extent of inventory behavior is reduced markedly. ${ }^{18}$

Although these inventory regressions provide some direct evidence of in-

18. We have also re-estimated (15) while excluding all one-week sales. This allows us to determine what inventory behavior is associated with multi-week sales. Generally, the coefficients we obtain on $\ln \left(1+H_{\text {own, } i t}\right)$ and $\ln \left(1+H_{\text {any }, t}\right)$ are lower than those reported in Table 5 , which combines the one-week and multi-week sales. 
ventory behavior, we also wish to know whether this can explain the upward bias in the chained Törnqvist index. To this end, in figure 5.1 we graph the "inventory effect" against the index bias, measured as the difference between the chained Törnqvist and the true COL index (where both of these are averaged over all weeks in 1993, and using the modal price in 1993 as the base). The "inventory effect" in equation (22) is measured using the coefficients on the first row for each region in table 5.5; that is, ignoring the advertising and display variables. The means for $\ln \left(1+H_{\text {own }, i t}\right)$ and $\ln (1+$ $H_{\text {any }, t}$ ) in equation (22) are now computed over the entire sample (i.e., for both positive and zero observations). This will capture not only the average value of these variables when positive but also the number of times that sales occur. We graph the average "inventory effects" against the index bias for the ten regions in figure 5.1 and for the 580 individual stores over which equation (22) could be estimated in figure 5.2.

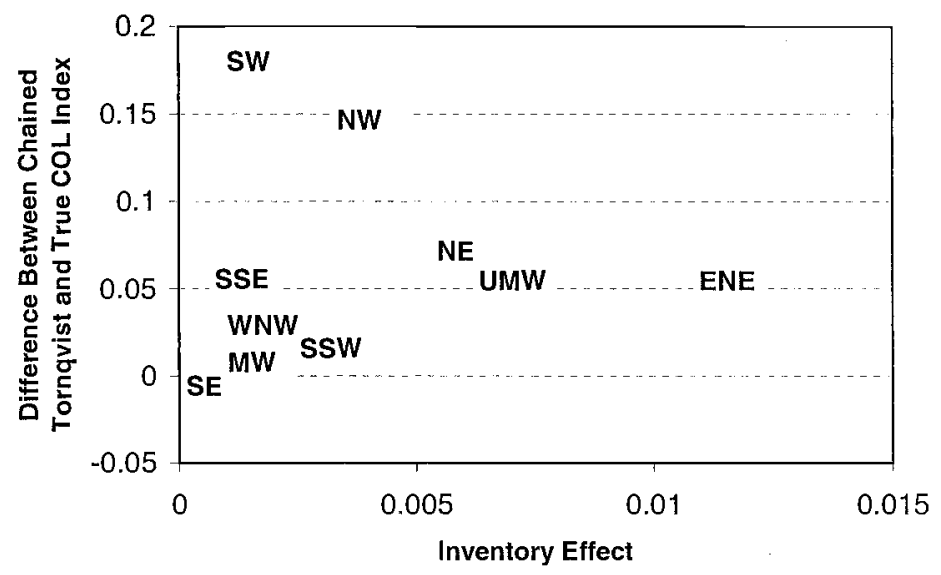

Fig. 5.1 Index bias and inventory effect: Regions

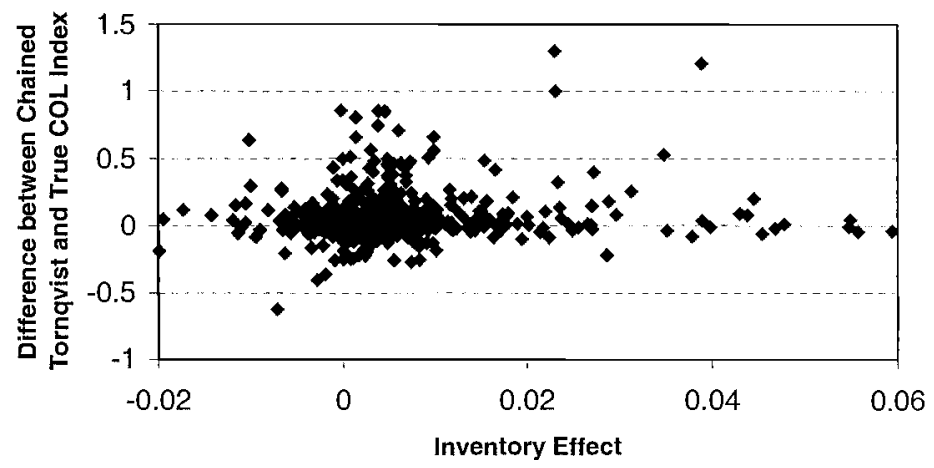

Fig. 5.2 Index bias and inventory effect: Stores 
In figure 5.1, there is only a weak positive relation between the "inventory effect" and the index bias; the correlation between these variables is 0.05 . The Southwest and Northwest have the highest bias of the chained Törnqvist index, and these both have coefficients of about 0.15 on $\ln \left(1+H_{\text {any,t }}\right)$ in table 5.5: although these effects are significant, they are not the largest coefficients that we find on inventory behavior. Conversely, the East Northeast region is shown as having the highest "inventory effect" in figure 5.1, and although it has a nonnegligible bias of the chained Törnqvist index in table 5.4, this bias is not the largest across regions.

However, when we look across individual stores in figure 5.2, the evidence for a positive relationship between inventory behavior and index bias is more apparent. The correlation between these two variables is 0.12 , which is significantly different from zero at the 1 percent level (with $N=580$ ). Thus, there are some stores that display both strong inventory behavior and a pronounced upward bias of the chained Törnqvist index. The three stores shown in figure 5.2 whose index bias exceeds unity are all in the Northeast and East Northeast regions; and in addition, twenty out of the top twentyfive stores with highest "inventory effects" are also in these two regions. Generally, the shopping patterns of the Northeast regions show marked inventory behavior and an upward bias of the chained Törnqvist, supporting the idea that such behavior causes the upward bias.

\subsection{Conclusions}

The data on tuna show substantial high-frequency variation in price and substantial response of consumer demand to this variation in price, suggesting inventory behavior. A true COL index in this context, as derived in section 5.2, must compare all prices over one planning horizon to all prices in another, (e.g., it must compare one year to the next). This differs from the conventional approach taken at the BLS, which is to compute price indexes in each month. Averaging over a month, as the BLS does, is a step toward aligning price measurement with the consumption rather than the shopping period. However, the month might not be the correct planning horizon. Moreover, even if it were, the results of section 5.2 show that the arithmetic average of prices is not the correct summary statistic to input into a COL index.

We find that the fixed-base Törnqvist, computed weekly and then averaged over a year, can adequately measure the true COL index (which is itself a Törnqvist formula). That is, the fixed-base Törnqvist captures the reduction in the COL that arises when consumers economize by substituting toward goods whose price is low. Conversely, the chained Törnqvist gives too much weight to price increases that follow the end of sales, and it is upward biased.

The upward bias of the chained Törnqvist can be explained by purchases for storage rather than consumption. During sales, some of the increase in 
demand corresponds to purchases for storage, as supported by our regression results. In particular, we find that purchases are increasing in time to the next sale. This finding is consistent with a forward-looking consumer engaging in storage. This evidence of forward-looking behavior is somewhat undermined by accounting for advertisements. Nevertheless, we find a link between inventory behavior - especially in the Northeast - and the upward bias of the chained Törnqvist. It follows that the chained approach is to be avoided when using high-frequency scanner data, and a fixed-base Törnqvist (or the true COL index) should be used instead.

\section{Appendix}

\section{Proof of Theorem}

Taking the log of equation (8), we obtain

$$
\begin{aligned}
\ln (\mathrm{COL})= & \frac{1}{2}\left[\ln E\left(p^{1}, z^{1}, U^{1}\right)-\ln E\left(p^{0}, z^{1}, U^{1}\right)+\ln E\left(p^{1}, z^{0}, U^{0}\right)\right. \\
& \left.-\ln E\left(p^{0}, z^{0}, U^{0}\right)\right] \\
= & \frac{1}{2}\left[\sum_{t=1}^{T}\left(\alpha_{t}^{1}+\alpha_{t}^{0}\right) \ln \left(\frac{p_{t}^{1}}{p_{t}^{0}}\right)+\sum_{s=1}^{T} \sum_{t=1}^{T} \gamma_{s t} \ln p_{s}^{1} \ln p_{t}^{1}-\sum_{s=1}^{T} \sum_{t=1}^{T} \gamma_{s t} \ln p_{s}^{0} \ln p_{t}^{0}\right] \\
= & \frac{1}{2}\left[\sum_{t=1}^{T}\left(\alpha_{t}^{1}+\alpha_{t}^{0}\right) \ln \left(\frac{p_{t}^{1}}{p_{t}^{0}}\right)+\sum_{s=1}^{T} \sum_{t=1}^{T} \gamma_{s t}\left(\ln p_{s}^{1}+\ln p_{t}^{0}\right)\left(\ln p_{t}^{1}-\ln p_{t}^{0}\right)\right] \\
= & \frac{1}{2}\left[\sum_{t=1}^{T}\left(s_{t}^{1}+s_{t}^{0}\right) \ln \left(\frac{p_{t}^{1}}{p_{t}^{0}}\right)\right]
\end{aligned}
$$

where the second line follows when we use the translog formula in equations (4) and (5), the third line follows from simple algebra, and the final line follows from the share formula in equation (7).

\section{References}

Alterman, William F., W. Erwin Diewert, and Robert C. Feenstra. 2000. International price indexes and seasonal commodities. Washington, D.C.: U.S. Department of Labor, Bureau of Labor Statistics.

Betancourt, Roger R., and David Gautschi. 1992. The demand for retail products and the household production model: New views on complementarity and substitution. Journal of Economic Behavior and Organization 17:257-75.

Betancourt, Roger R., and Margaret Malanoski. 1999. An estimable model of su- 
permarket behavior: Price, distribution services, and some effects of competition. Empirica 26:55-73.

Caves, Douglas W., Laurits R. Christensen, and W. Erwin Diewert. 1982a. The economic theory of index numbers and the measurement of input, output, and productivity. Econometrica 50 (11): 1393-414.

1982b. Multilateral comparisons of output, input, and productivity using superlative index numbers. Economic Journal 92 (March): 73-86.

Chevalier, Judith A., Anil K. Kashyap, and Peter E. Rossi. 2000. Why don't prices rise during periods of peak demand? Evidence from scanner data. NBER Working Paper no. 7981. Cambridge, Mass.: National Bureau of Economic Research.

Diewert, W. Erwin. 1976. Exact and superlative index numbers. Journal of Econometrics 4:115-45.

- 1978. Superlative index numbers and consistency in aggregation. Econometrica 46 (4): 883-900.

- 1999. Index number approaches to seasonal adjustment. Macroeconomic Dynamics 3:48-68.

. 2000. The Consumer Price Index and index number purpose. Discussion Paper no. 00-02. University of British Columbia, Department of Economics. Available at [http://web.arts.ubc.ca/econ/diewert/hmpgdie.htm], forthcoming in Journal of Economic and Social Measurement. Reinsdorf, Marshall B. 1999. Using scanner data to construct CPI basic component indexes. Journal of Business and Economic Statistics 17 (2): 152-60.

Triplett, Jack. 1998. Elementary indexes for a consumer price index, In Proceedings of the fourth meeting of the International Working Group on Price Indices, ed. Walter Lane, 176-97. Washington, D.C.: U.S.Department of Labor, Bureau of Labor Statistics.

van Heerde, Harald J., Peter S. H. Leeflang, and Dick R. Wittink. 2000. The estimation of pre- and post-promotion dips with store-level scanner data. Journal of Marketing Research 37 (3): 383-95.

\section{Comment Marshall B. Reinsdorf}

\section{Overview}

This paper provides a thoughtful treatment of one of the challenges that arise in using scanner data to produce price indexes. Scanner data sets are generally highly disaggregated, with weekly observations on a large number of varieties of each item in a large number of stores. Products at this level of disaggregation are often so similar that they are highly substitutable for one another, but the item that these authors consider, canned tuna fish, has the distinction of exhibiting high substitution across time. In particular, temporary price reductions have a large effect on the timing of purchases of tuna because it has a low cost of storage.

Marshall B. Reinsdorf is an economist at the U.S. Bureau of Economic Analysis.

The views expressed in this comment are those of the author and should not be attributed to the Bureau of Economic Analysis. 
Fortunately, Feenstra and Shapiro recognize that the static model underlying standard cost-of-living (COL) index theory is unsuitable when many purchases are for storage rather than current consumption. They therefore consider a model in which purchases are for inventory, and consumption decisions are subject to an inventory constraint. The authors refer to this as a "household production" model, but it differs from the usual household production function setup because additional inputs, such as the consumer's time, are not required to produce the consumption good. The twostage model can therefore be simplified into a more useful one-stage model, in which purchases from different weeks are effectively substitutes in a utility function that covers the entire planning period.

To estimate a COL index for this model, the authors specify an interval of one year for the planning period and a translog functional form for the expenditure function. A COL index for the year can then be calculated as a Törnqvist index that in effect treats purchases from different weeks as inputs into the household production process for the year.

Cost-of-living indexes for ten regions of the United States and the United States as a whole that compare all of 1993 to the modal prices of 1992 and 1993 average about 0.96 , compared with fixed-base Laspeyres indexes, which average around 1. Although this indicates substantial substitution, the tendency of tuna fish to experience large swings in prices and quantities led me to anticipate an even larger difference. Furthermore, the authors find that a fixedbase Törnqvist index, which would be more practical for statistical agencies to calculate, is on average less than 1 percent higher than the "true" COL index. Since the fixed-base Törnqvist index ignores substitution between weeks, this result suggests that allowing only for substitution between varieties and stores captures about three-quarters of the gains from substitution.

Substitution between weeks has another effect besides causing upward bias in the annual average of direct Törnqvist indexes: it makes weeks nonseparable from each other. If current quantities have stable relationships to current prices, a chained Törnqvist index can be expected to agree closely with a direct Törnqvist index. For a storable commodity like tuna, on the other hand, sensitivity of current quantities to past (or expected future) prices is likely to cause chained indexes to "drift." Indeed, the empirical results in the paper show substantial upward drift for chained Törnqvist indexes and very large drift for chained Laspeyres indexes.

Variability in expenditure shares due to advertisements and in-store displays also contributes to the drift that is observed for the chained indexes. Advertisements and in-store displays cause large increases in quantities that consumers buy, especially when they occur in conjunction with a sale. Moreover, in some regions they tend to occur in the last week of sales that last longer than one week, causing the chained Törnqvist index to give more weight to the reversion of the sale price to the regular price than to the reduction to the price. 
The final major section of the paper seeks empirical evidence on inventory behavior by examining the effect of the length of time until the next sale on the quantity sold. In many of the regions that the authors examine, consumers do seem to stock up more during a sale when the next sale is further away. Furthermore, a positive relationship exists between the inventory effect at the store level (which partly reflects the frequency of sales in the store) and the upward drift of chained Törnqvist indexes. Nevertheless, the addition of variables for the presence of advertisements and displays leaves only the Northeast with a significant effect of time-until-the-next-sale.

\section{Discussion}

Accounting for substitution between weeks by means of a Törnqvist index covering the entire planning interval is a clever and useful solution to the problem of how to treat storable commodities in a COL index. Research on more detailed models of inventory behavior would, however, be valuable. The authors obtain their eminently practical solution from a simplified model. In particular, some consumption in a planning interval is likely to be from inventories carried over from previous planning intervals, and some purchases are likely to be intended for carry-over to the next planning interval. Ignoring this allows the authors to force an essentially dynamic problem back into the framework of static COL index theory.

In addition, the empirical finding that advertising and in-store displays have large effects on purchases suggests that imperfect information plays an important role in this retail market. A model of inventory management behavior under imperfect information would therefore capture an important feature of this market that is beyond the scope of the model in the present paper.

Imperfect information may also be the basis for an alternative theory of how to aggregate prices from adjacent weeks for a single product. The simple technique of aggregating prices from adjacent weeks by means of unit values is justified if consumers regard purchases in those weeks as perfect substitutes for each other. However, perfect substitutability implies that all sales occur at the lowest price, making aggregation unnecessary. To be logistically consistent, therefore, an approach that treats purchases at varying prices in adjacent weeks as perfect substitutes requires a model in which consumers do not acquire complete information.

Turning to the findings in this paper on high frequency chaining, the conclusion that high-frequency chaining must be avoided for products like tuna fish is worth emphasizing. Nonseparabilities and consumers' responses to promotional information are likely to make the data behave as if preferences were unstable from week to week. Chained indexes can be expected to perform poorly under this circumstance. Indeed, in a footnote the authors report that chained Laspeyres indexes grow by factors of 2 to 20, even though the fixed-base Laspeyres indexes are around 1. Even the chained 
Törnqvist index, a formula that usually performs well, exhibits upward drift of three or four percent at the national level and up to 15 percent in the regions.

Finally, I have three minor quibbles with this paper. First, the index formula that the authors call "chained Laspeyres"-equation (12) - is mislabeled because it holds constant relative expenditures rather than quantities. To keep quantities constant in a chained index, expenditure weights must be adjusted in proportion to the price change that has occurred since the base period. The Bureau of Labor Statistics, for example, updates each quote's expenditure weight in this way. The authors omit this updating step in their calculations of the chained Laspeyres index because it renders the comparison with the fixed-base Laspeyres index uninteresting: Unless the chained index includes observations absent from the fixed-base index, no discrepancy can exist between the indexes. The authors' "alternative chained Laspeyres index" has a formula that is consistent with its label, however, and it should be compared to the authors' chained Törnqvist index.

Second, I would have liked to see a discussion of the importance and treatment of missing values. Scanner data sets omit products that no one buys in a week, and in very disaggregated data, exit and entry of products is common. Consequently, missing values are often a problem in store-level scanner data. If products that exit or enter command sizable portions of total expenditures when they are present, a researcher may choose to use chained indexes because they can include prices for products that exit or enter. I presume that the chained indexes in this paper differ from their fixedbase counterparts only because of their functional form and not because they include prices for products that exit or enter. Statistics on product exit and entry are also important because they can indicate the presence of a potential source of bias. In particular, Feenstra (1994) shows that coverage of a diminished portion of consumers' expenditures on an item biases a price index upward compared to a true COL index.

Third, I think the regression analysis should include checks for some covariances of the error terms. In particular, store effects or manufacturers' advertising campaigns may cause positive cross-sectional covariances in errors. In addition, unusually high sales in the recent past may tend to depress current sales. Evidence of this would be an additional indication of inventory behavior.

\section{Reference}

Feenstra, Robert C. 1994. New product varieties and the measurement of international prices. American Economic Review 84 (March): 157-77. 
